\title{
Efficacy of propranolol and pingyangmycin, respectively, combined with pulsed dye laser on children with hemangioma
}

\author{
ZHIYONG HUANG, NING ZHANG, HANXIN CAI and KUNHUI LUO
}

\author{
Department of Vascular Surgery, The 3rd Affiliated Hospital of Shenzhen University, \\ Shenzhen, Guangdong 518000, P.R. China
}

Received September 6, 2019; Accepted November 4, 2019

DOI: $10.3892 /$ etm.2019.8314

\begin{abstract}
Clinical efficacy of propranolol and pingyangmycin, respectively, combined with pulsed dye laser in the treatment of children with hemangioma was analyzed, to provide a new therapeutic idea for their clinical treatment. A total of 120 children with hemangioma were selected into the study. Children treated with propranolol combined with pulsed dye laser were in group $\mathrm{A}$, those treated with pingyangmycin combined with pulsed dye laser were in group B, and 60 healthy children were selected as control group (group C). Blood samples of children were taken before and after treatment for miR-4295 detection. The expression of miR-4295 was observed after treatment, and the total clinical remission rate and adverse reactions after treatment were compared between the two groups. The tumor volume of the two groups was significantly reduced after treatment, with statistically significant difference $(\mathrm{P}<0.05)$; miR-4295 expression was reduced in the two groups $(\mathrm{P}<0.05)$; adverse reactions in propranolol group were less than pingyangmycin group during treatment $(\mathrm{P}<0.05)$. Propranolol and pingyangmycin, respectively, combined with pulsed dye laser had ideal efficacy on hemangioma in children. Moreover, miR-4295 was highly expressed in children with hemangioma, and the expression level reduced after two methods of treatment. However, adverse reactions in propranolol group were less and its safety was higher.
\end{abstract}

\section{Introduction}

Morbidity of children with hemangioma has gradually increased, ranging from 3 to $8 \%$. Premature delivery, low birth weight, placental dysfunction, elderly parturient women, amniocentesis and fetal hypoxia are risk factors for the occurrence of hemangioma in children, with obvious family medical

Correspondence to: Dr Zhiyong Huang, Department of Vascular Surgery, The 3rd Affiliated Hospital of Shenzhen University, 47 Youyi Road, Shenzhen, Guangdong 518000, P.R. China E-mail: i8v8hs@163.com

Key words: children with hemangioma, pingyangmycin, pulsed dye laser, miR-4295 history $(1,2)$. It usually occurs at birth or within 3 to 6 months after birth, often in the head, face and neck. Hemangioma, as one of the most common benign tumors in children, has different treatment methods due to its different locations, including laser and medical surgical treatment (3). The medical treatment includes oral propranolol and local injection of pingyangmycin. Propranolol is a non-selective $\beta$-adrenoceptor blocker, which can achieve obvious efficacy 6 months after continuous use, but has the risk of causing serious complications such as bradycardia (4), while pingyangmycin is a kind of cytotoxic glycopeptide antitumor antibiotic, and local injection can shorten the degeneration process of hemangioma (5). These two drugs are used as the basic drugs for hemangioma in children, and both have certain adverse reactions in the process of drug use alone. Pulsed dye laser (PDL) is a liquid laser with fluorescent organic dye as medium, which can promote coagulation degeneration of hemoglobin, necrosis of vascular endothelial cells and vascularization embolism, thus selectively damaging microvessels, and can treat skin lesions more effectively than other types of lasers (6). Furthermore, it has been proven that miRNAs can affect angiogenesis. miRNA-4295, a new oncogenic miRNA, is highly expressed in many tumor tissues (7). Some studies showed that propranolol promoted apoptosis by inhibiting the expression of miR-4295 during the treatment of hemangioma (8). In this study, pulsed dye laser and two drugs, respectively, were combined to treat hemangioma in children, to analyze the efficacy, and compare the two treatment methods to establish the one more suitable for clinical use, and to further observe the effect of miR-4295 in the two treatment methods.

\section{Patients and methods}

Clinical data. From January 2017 to January 2019, 120 children with hemangioma admitted to the 3rd Affiliated Hospital of Shenzhen University (Shenzhen, China) were selected. Among them, 60 received propranolol combined with pulsed dye laser therapy (group A), the other 60 received pingyangmycin combined with pulsed dye laser therapy (group B), and 60 normal children who underwent physical examination at the same time were selected as control group (group C). The study was approved by the Ethics Committee of the 3rd Affiliated Hospital of Shenzhen University. Signed informed consents were obtained from the parents of the child patients. 
Table I. Primer sequences.

$\operatorname{miR}-4295$

\begin{tabular}{lll}
\hline Reverse & 5'-CAGTGCAATGTTTTCCTTGCC-3' & 5'-ATT GGA ACG ATA CAG AGA AGA TT-3' \\
Forward & 5'-GTAGGAACAGTCTAGTTTCTTAGCC-3' & 5'-GGA ACG CTT CAC GAA TTT G-3'
\end{tabular}

Inclusion and exclusion criteria. The age of children involved in this study was 1-6 months. All the children were first time hospitalized. Hemangioma was definitely diagnosed by clinical examination, B-ultrasound, CT plain scan, MRI or X-ray examination before treatment, and all occurred on the body surface. Exclusion criteria were as follows: i) Children with other tumor history; ii) children who had received other treatments before this study; iii) children with scar constitution; iv) children with allergic history; v) children with cardiovascular diseases such as sinus bradycardia and atrioventricular block; vi) children with skin ulcer or infection at the treatment site that were not suitable for laser treatment; vii) children with dysphoria and coordination difficulties.

Methods. Altogether 120 children were treated with $595 \mathrm{~nm}$ pulsed dye laser (model: Vbeam595nm; Candela Company). First, the children were locally given $2 \%$ lidocaine for surface anesthesia. The laser wavelength was adjusted to $595 \mathrm{~nm}$ and the pulse width was $0.45-20 \mathrm{msec}$. Appropriate treatment parameters were selected according to the location of hemangioma. After irradiation, they were ice compressed for $30 \mathrm{~min}$ and zinc oxide cream was used until the petechiae caused by laser disappeared, with an interval of 1 month (9). At the time of laser treatment, children in group A were treated with propranolol [Ruiyang Pharmaceutical (Shanghai) Co., Ltd.; SFDA approval no. H31021347, specification: $10 \mathrm{mg}$, they were orally administered 3 times a day, $0.5 \mathrm{mg} / \mathrm{kg}$ each time, if there were no adverse reactions, the dose was doubled to $1 \mathrm{mg} / \mathrm{kg} /$ day after 3 days and was changed to $2 \mathrm{mg} / \mathrm{kg} /$ day to maintain (10) 3 days after further treatment. By contrast, children in group B were given pingyangmycin (Hanhui Pharmaceutical Co., Ltd; SFDA approval no. H20059039, specification: $8 \mathrm{mg}$ ) $8 \mathrm{mg}$ mixed with $2 \mathrm{ml}$ normal saline for local injection of lesions, twice/15 days.

Blood samples were collected from children in the three groups before and after treatment. Real-time fluorescence quantitative PCR (RT-PCR) was used to detect the expression of miR-4295 (the kit was purchased from Beijing Kangjiahongyuan Biotechnology Co., Ltd.). Total RNA was extracted in strict accordance with the instructions of TRIzol kit (Anhui Jingke Biology Co., Ltd.; art. no. WLA088a). RNA was reverse transcribed into cDNA according to the instruction manual of reverse transcription kit (Beijing Protein Innovation; art. no. BPI01030), and then amplification was carried out using amplification kit (Shenzhen Ziker Biotechnology Co., Ltd.; art. no. TQ2104-01). The primer sequence was synthesized by Shanghai Rebiosci Biotechnology Co., Ltd. Details are shown in Table I. First, they were pre-denatured at $94^{\circ} \mathrm{C}$ for $30 \mathrm{sec}$, denatured at $94^{\circ} \mathrm{C}$ for $5 \mathrm{sec}$, annealed and extended at $60^{\circ} \mathrm{C}$ for $30 \mathrm{sec}$, with 40 cycles. The experiment was carried out three times,
U6 was used for internal reference and data were analyzed by $2^{-\Delta \mathrm{CT}}$.

Criterion for observation indicators and efficacy. After 6 months of treatment, the efficacy and adverse reactions of children in the two groups were observed and compared. According to Achauer grading evaluation standard (11), hemangioma is divided into four levels: Level I: Hemangioma tumor volume shrinks or tumor color fades $<25 \%$; level II: Hemangioma tumor volume shrinks or tumor color fades by $25-50 \%$; level III: Hemangioma tumor volume shrinks or tumor color fades by $51-75 \%$; level IV: Hemangioma tumor volume shrinks or tumor color fades $76-100 \%$. Level I is defined as no obvious efficacy, level II-III as effective, and level IV as markedly effective. Remission rate = markedly effective percentage + effective percentage.

Statistical methods. All the data used in this study were analyzed by SPSS 24.0. Measurement data were expressed as mean \pm standard deviation, the enumeration data were expressed as percentage, the comparison of the enumeration data was performed by Chi-square test, the comparison between the two groups was performed by t-test, the comparison between multiple groups was performed by variance analysis, and the diagnostic value was performed by ROC curve analysis. $\mathrm{P}<0.05$ was considered statistically significant between the two groups.

\section{Results}

Comparison of clinical data. There was no significant difference in gestational age, age (month), sex, body weight, white blood cells, location, course of disease, delivery mode and tumor type between group A, group B (research group) and group $\mathrm{C}$ (control group) $(\mathrm{P}>0.05)$, proving that children in the three groups were comparable, as shown in Table II.

Comparison of the total remission rate of children in the two groups 6 months after treatment. Through analysis, we found that children in the two groups had obvious efficacy after drug combination, respectively, and there was no obvious difference in efficacy between the two groups $(\mathrm{P}<0.05)$ (Table III).

Comparison of the incidence rate of adverse reactions between children in the two groups. The adverse reactions such as decreased heart rate, fever, gastrointestinal symptoms and scar formation were compared between the two groups. The incidence rate of adverse reactions in group A was $13.33 \%$, while that in group B was $31.67 \%$, with statistically significant difference $(\mathrm{P}<0.05)$ (Table IV). 
Table II. Comparison of clinical data [n (\%)].

\begin{tabular}{|c|c|c|c|c|c|}
\hline Features & Group A $(n=60)$ & Group B $(n=60)$ & Group C $(n=60)$ & $\chi^{2}$ or $\mathrm{F}$ & P-value \\
\hline Gestational age (weeks) & $33.51 \pm 5.84$ & $34.17 \pm 6.22$ & $34.53 \pm 5.79$ & 0.453 & 0.636 \\
\hline Age (month) & $4.26 \pm 1.72$ & $3.83 \pm 2.13$ & $4.19 \pm 1.56$ & 0.965 & 0.383 \\
\hline \multicolumn{6}{|l|}{ Sex } \\
\hline Male & $21(35.00)$ & $23(38.33)$ & $28(46.67)$ & & \\
\hline Female & $39(65.00)$ & $37(61.67)$ & $32(53.33)$ & & \\
\hline Weight (kg) & $5.37 \pm 2.21$ & $5.31 \pm 2.02$ & $5.41 \pm 1.98$ & 0.035 & 0.965 \\
\hline White blood cells $\left(10^{9} / 1\right)$ & $7.12 \pm 2.37$ & $7.24 \pm 2.08$ & $7.18 \pm 1.64$ & 0.051 & 0.950 \\
\hline \multicolumn{6}{|l|}{ Location } \\
\hline Maxillofacial region & $22(36.67)$ & $24(40.00)$ & & & \\
\hline Trunk & $15(25.00)$ & $10(16.67)$ & & & \\
\hline Limbs & $17(28.33)$ & $18(30.00)$ & & & \\
\hline Multiple parts of the body & $6(10.00)$ & $8(13.33)$ & & & \\
\hline Course of disease (month) & $3.41 \pm 2.26$ & $3.19 \pm 2.14$ & & 0.548 & 0.585 \\
\hline \multicolumn{6}{|l|}{ Delivery mode } \\
\hline Eutocia & $42(70.00)$ & $38(63.33)$ & $46(76.67)$ & & \\
\hline Cesarean section & $18(30.00)$ & $22(36.67)$ & $14(23.33)$ & & \\
\hline \multicolumn{6}{|l|}{ Tumor classification } \\
\hline Capillary hemangioma & $41(68.33)$ & $44(73.33)$ & & & \\
\hline Cavernous hemangioma & $12(20.00)$ & $10(16.67)$ & & & \\
\hline Plexiform hemangioma & $7(11.67)$ & $6(10.00)$ & & & \\
\hline
\end{tabular}

Table III. Comparison of efficacy between group A and group B.

\begin{tabular}{|c|c|c|c|c|c|}
\hline Group & Number of cases & Markedly effective & Effective & Ineffective & Total remission rate \\
\hline Group A & 60 & $43(71.67)$ & $15(25.00)$ & $2(3.33)$ & $58(96.67)$ \\
\hline Group B & 60 & $40(66.67)$ & $17(28.33)$ & $3(5.00)$ & $57(95.00)$ \\
\hline$\chi^{2}$ value & & & & & 0.209 \\
\hline P-value & & & & & 0.648 \\
\hline
\end{tabular}

Table IV. Comparison of adverse reactions n (\%).

\begin{tabular}{|c|c|c|c|c|c|c|}
\hline Group & $\begin{array}{c}\text { Number of } \\
\text { cases }\end{array}$ & $\begin{array}{c}\text { Decreased } \\
\text { heart rate } \\
{[\mathrm{n}(\%)]}\end{array}$ & $\begin{array}{l}\text { Fever } \\
{[\mathrm{n}(\%)]}\end{array}$ & $\begin{array}{c}\text { Gastrointestinal } \\
\text { symptoms } \\
{[\mathrm{n}(\%)]}\end{array}$ & $\begin{array}{c}\text { Scar } \\
\text { formation } \\
{[\mathrm{n}(\%)]}\end{array}$ & $\begin{array}{c}\text { Occurrence of } \\
\text { adverse reactions } \\
{[\mathrm{n}(\%)]}\end{array}$ \\
\hline Group A & 60 & $2(3.33)$ & $2(3.33)$ & $3(5.00)$ & $1(1.67)$ & $8(13.33)$ \\
\hline Group B & 60 & $3(5.00)$ & $6(10.00)$ & $8(13.33)$ & $2(3.33)$ & $19(31.67)$ \\
\hline$\chi^{2}$ value & & & & & & 5.783 \\
\hline P-value & & & & & & 0.016 \\
\hline
\end{tabular}

Detection of the expression level of miR-4295 in hemangioma tissues of children. Blood samples of 120 children with hemangioma and 60 normal children were collected before treatment. The expression level of miR-4295 was detected by real-time fluorescence quantitative PCR, and the results showed that the expression level of miR-4295 in children with hemangioma was significantly higher than that in normal samples $(\mathrm{P}<0.0001)$ (Fig. 1).

Prediction of hemangioma through miR-4295. Real-time fluorescence quantitative PCR (RT-PCR) was used to detect the expression level of miR-4295 in blood of children with 


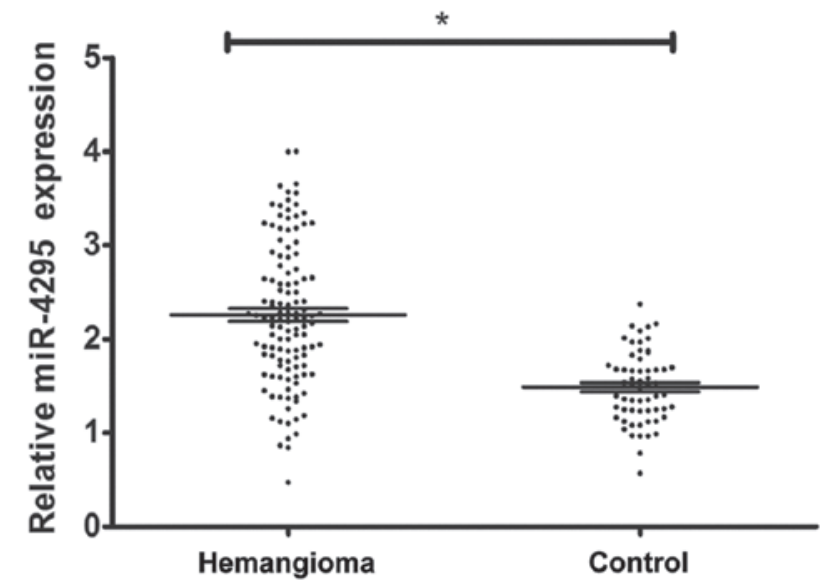

Figure 1. Expression level of miR-4295 in children with hemangioma. In the comparison of miR-4295 expression level between the children with hemangioma and healthy controls, the expression level of miR-4295 in children with hemangioma was significantly higher than that in healthy controls $\left({ }^{*} \mathrm{P}<0.05\right)$.

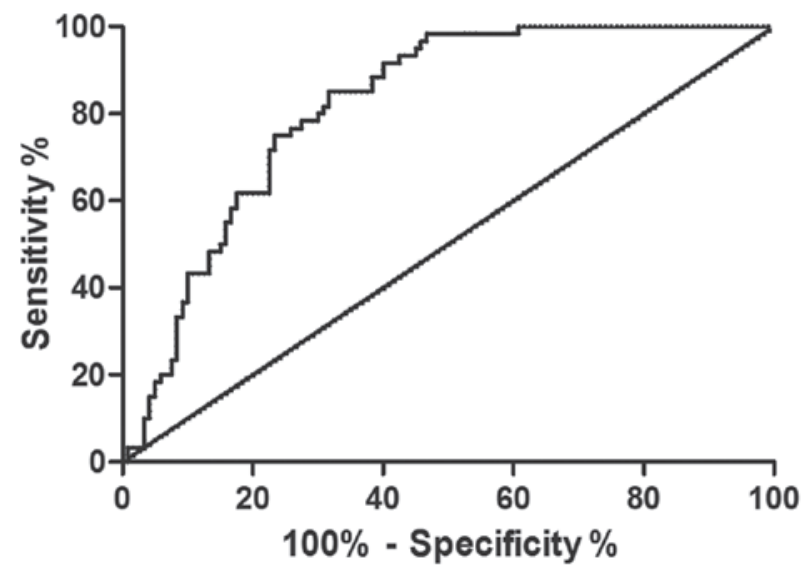

Figure 2. Early diagnostic value of miR-4295 for hemangioma.

hemangioma, and ROC curve analysis was drawn. Area under miR-4295 curve was 0.817 , sensitivity was $85.00 \%$, specificity was $68.33 \%$, cut-off value was 1.88 , and $95 \%$ CI was 59.22-76.52\% (Fig. 2).

Detection of the expression level of miR-4295 before and after treatment in groups $A$ and $B$. The expression of miR-4295 in blood samples of children in group A was $2.29 \pm 0.77$ before treatment and $1.49 \pm 0.36$ after treatment, and the expression of miR-4295 in blood samples of children in group B was $2.33 \pm 0.73$ before treatment and $1.39 \pm 0.47$ after treatment, with statistically significant difference $(\mathrm{P}<0.01)$ (Figs. 3 and 4$)$.

As shown in Fig. 1, the expression level of miR-4295 in children with hemangioma was significantly higher than that in normal children, and the expression level of miR-4295 significantly reduced after the combination of propranolol and pingyangmycin with PDL, respectively.

Correlation analysis of the expression level of miR-4295 and clinical pathology of children with hemangioma in the two groups. Correlation between miR-4295 and clinical characteristics of the children in the research groups was

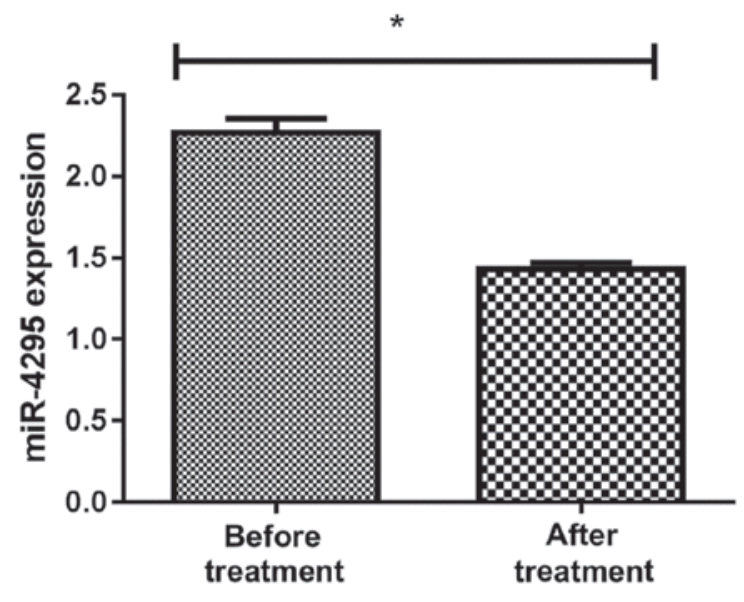

Figure 3. Expression of miR-4295 before and after treatment in group A. Expression level of miR-4295 in children from group A after treatment was significantly lower than that before treatment $\left({ }^{*} \mathrm{P}<0.01\right)$.

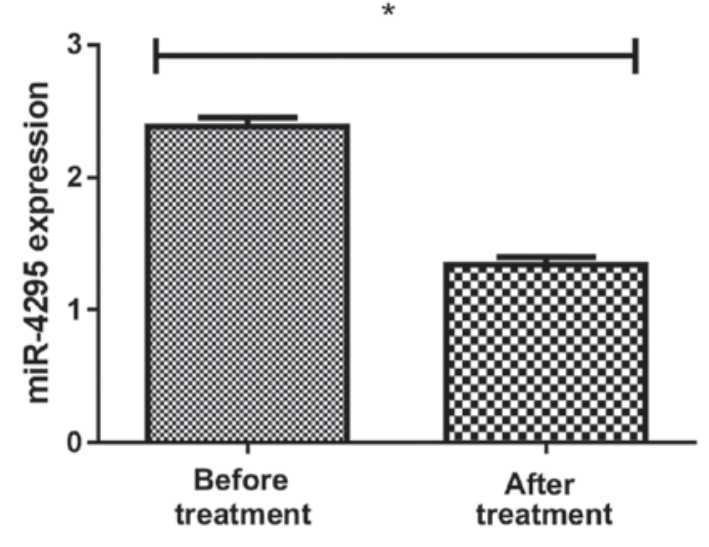

Figure 4. Expression of miR-4295 before and after treatment in group B. Expression level of miR-4295 in children from group B after treatment was also significantly lower than that before treatment $\left({ }^{*} \mathrm{P}<0.01\right)$.

analyzed. The results of variance analysis showed that the expression of miR-4295 in different tumor types was significantly different $(\mathrm{P}<0.01)$, and the comparison of LSD showed that the expression of miR-4295 in cavernous hemangioma was significantly higher than that in capillary hemangioma $(\mathrm{P}<0.05)$. The analysis revealed that the course of disease, gestational age and tumor type were related to the expression of miR-4295 $(\mathrm{P}<0.05)$, while sex and location of occurrence were not significantly related to the expression of miR-4295 (P>0.05) (Table V).

\section{Discussion}

Hemangioma in children is a benign vascular tumor caused by abnormal proliferation of endothelial cells and peripheral cells. It is the most common tumor in infants (12), especially those aged under one year. Tumors show unique life cycle and can be divided into three stages: proliferation stage, stable stage and dissipation stage (13). It is characterized by rapid proliferation in early postnatal period and spontaneous and slow regression afterwards. Different from other tumors, they have unique regression ability after diffusion, which often 
Table V. Correlation analysis of the expression level of miR-4295 and clinical pathology of children with hemangioma in the two groups.

\begin{tabular}{|c|c|c|c|c|}
\hline Features & $\mathrm{N}$ & miR-4295 level & tor $F$ & P-value \\
\hline Course of disease (month) & & 3.090 & 0.003 & \\
\hline$<3$ & 49 & $2.42 \pm 0.54$ & & \\
\hline$\geq 3$ & 71 & $2.71 \pm 0.48$ & & \\
\hline Gestational age (weeks) & & & 3.100 & 0.002 \\
\hline $32.83 \pm 4.16$ & 89 & $2.58 \pm 0.56$ & & \\
\hline $39.51 \pm 2.27$ & 31 & $2.24 \pm 0.41$ & & \\
\hline Sex & & & 0.209 & 0.835 \\
\hline Male & 21 & $2.37 \pm 0.74$ & & \\
\hline Female & 39 & $2.33 \pm 0.69$ & & \\
\hline Location & & & 0.172 & 0.915 \\
\hline Maxillofacial region & 46 & $2.29 \pm 0.81$ & & \\
\hline Trunk & 25 & $2.41 \pm 0.52$ & & \\
\hline Limbs & 35 & $2.34 \pm 0.58$ & & \\
\hline Multiple parts of the body & 14 & $2.33 \pm 0.64$ & & \\
\hline Tumor classification & & & 7.944 & $\mathrm{P}<0.01$ \\
\hline Capillary hemangioma & 85 & $2.18 \pm 0.42$ & & \\
\hline Cavernous hemangioma & 22 & $2.63 \pm 0.57$ & & \\
\hline Plexiform hemangioma & 13 & $2.25 \pm 0.61$ & & \\
\hline
\end{tabular}

leads primary health care providers to think that they will be solved without intervention. Unfortunately, severe hemangiomas will rapidly develop complications, resulting in pain, functional damage or permanent deformity (14). Hemangioma is a self-limiting tumor, and the tumors that usually need to be treated include periorbital region, central face, airway, skin fold and anal region, as well as the high-risk parts of ulcer, dysfunction or deformity, which will affect the normal growth and development of children, and will have serious impact on the appearance and psychology of children.

Propranolol is a non-selective $\beta$ receptor blocker commonly used clinically. In recent years, a large number of studies on the successful treatment of hemangioma with oral propranolol have been reported, making propranolol the first-line drug for the treatment of hemangioma (15-17). Pingyangmycin, as an antitumor antibiotic, forms thrombus in tumor blood sinus and causes fibrosis of the tumor body when injected into a tumor, which is a reliable and effective treatment method for children with hemangioma (18-20). With the rapid development of laser technology, it has been gradually applied to the treatment of clinical diseases. Through pulsed dye laser technology, hemoglobin is destroyed under laser selective photothermolysis. Early use can accelerate the transition from hemangioma to plateau or degeneration stage to prevent further growth of hemangioma, and has obvious efficacy on superficial hemangioma $(21,22)$. In this study, propranolol and pingyangmycin were, respectively, combined with pulsed dye laser to treat hemangioma in children. The results revealed that the two treatment methods had obvious efficacy, but the adverse reactions of propranolol combined with PDL in the treatment of hemangioma were less than those of pingyangmycin. In the later stage of treatment, the tumor volume of hemangioma in children significantly reduced and there was no other discomfort. The method is simple and convenient to operate in clinical application and is worth promoting. The expression level of miR-4295 before and after treatment was detected, and the expression level of miR-4295 in hemangioma specimens before treatment was significantly higher than that in normal specimens. After intervention by two methods, the expression level of miR-4295 in tumor tissues was found to be significantly lower than that before $(\mathrm{P}<0.05)$. This finding suggested that the two treatment methods might be mediated by miR-4295 to produce relevant effects. Through the detection of miR-4295, it was found that the expression of miR-4295 significantly increased in children and premature infants with different tumor types and course of disease over three months $(\mathrm{P}<0.05)$, while sex was not correlated with the expression of miR-4295 ( $P>0.05)$. In addition, the regulatory networks identified in previous studies included microRNA miR-9, miR-939 and let-7 families; these microRNA and deregulated genes had the most interaction in children with hemangioma, suggesting that they might play an important role in the molecular mechanism of disease (23). However, according to the results of this study, the expression of miR-4295 in hemangiomas obviously increased. Therefore, whether miR-4295 also had a mechanism of action in hemangiomas and played a part in the occurrence and development remained to be further studied. If miR-4295 is confirmed to be a new potential biomarker, it can be helpful for early screening and prognosis of hemangiomas in clinical practice.

The limitations to this study are that no basic research was carried out, thus, it is impossible to further understand how miR-4295 is related to hemangiomas, and at present impossible to judge which treatment method is more closely related 
to miR-4295. Further research is needed as well as relevant follow-up.

In conclusion, the clinical efficacy of propranolol and pingyangmycin combined with pulsed dye laser respectively in the treatment of children with hemangioma is ideal, and the adverse reactions of propranolol group are less and its safety is higher, and the process of clinical application should be comprehensively analyzed based on the actual situation. However, miR-4295 is highly expressed in children with hemangioma, and its expression level is reduced after two methods of treatment. The mechanism of miR-4295 on hemangiomas needs further study, to make miR-4295 a promising indicator for future diagnosis and treatment of hemangiomas.

\section{Acknowledgements}

Not applicable.

\section{Funding}

No funding was received.

\section{Availability of data and materials}

The datasets used and/or analyzed during the present study are available from the corresponding author on reasonable request.

\section{Authors' contributions}

$\mathrm{ZH}, \mathrm{NZ}$ and $\mathrm{HC}$ conceived and designed the study, and drafted the manuscript. ZH, NZ, HC and KL collected, analyzed and interpreted the experimental data. $\mathrm{ZH}$ revised the manuscript for important intellectual content. All authors read and approved the final manuscript.

\section{Ethics approval and consent to participate}

The study was approved by the Ethics Committee of the 3rd Affiliated Hospital of Shenzhen University (Shenzhen, China). Signed informed consents were obtained from the parents of the child patients.

\section{Patient consent for publication}

Not applicable.

\section{Competing interests}

The authors declare that they have no competing interests.

\section{References}

1. Castrén E, Salminen P, Vikkula M, Pitkäranta A and Klockars T: Inheritance patterns of infantile hemangioma. Pediatrics 138: e20161623, 2016.

2. de Jong S, Itinteang T, Withers AH, Davis PF and Tan ST: Does hypoxia play a role in infantile hemangioma? Arch Dermatol Res 308: 219-227, 2016.

3. Darrow DH, Greene AK, Mancini AJ and Nopper AJ; Section on dermatology, section on otolaryngology-head and neck surgery, and section on plastic surgery: Diagnosis and management of infantile hemangioma: Executive summary. Pediatrics 136: 786-791, 2015.
4. Léauté-Labrèze C, Hoeger P, Mazereeuw-Hautier J, Guibaud L, Baselga E, Posiunas G, Phillips RJ, Caceres H, Lopez Gutierrez JC, Ballona R, et al: A randomized, controlled trial of oral propranolol in infantile hemangioma. N Engl J Med 372: 735-746, 2015.

5. Zhang L, Yuan WE and Zheng JW: Pharmacological therapies for infantile hemangiomas: A clinical study in 853 consecutive patients using a standard treatment algorithm. Sci Rep 6: 21670, 2016.

6. Chinnadurai S, Sathe NA and Surawicz T: Laser treatment of infantile hemangioma: A systematic review. Lasers Surg Med 48: 221-233, 2016.

7. Nan YH, Wang J, Wang Y, Sun PH, Han YP, Fan L, Wang KC, Shen FJ and Wang WH: MiR-4295 promotes cell growth in bladder cancer by targeting BTG1: Am J Transl Res 8: 4892-4901, 2016.

8. Zhao F, Yang X, Xu G, Bi J, Lv R and Huo R: Propranolol suppresses HUVEC viability, migration, VEGF expression, and promotes apoptosis by downregulation of miR-4295. J Cell Biochem 120: 6614-6623, 2019.

9. Asilian A, Mokhtari F, Kamali AS, Abtahi-Naeini B, Nilforoushzadeh MA and Mostafaie S: Pulsed dye laser and topical timolol gel versus pulse dye laser in treatment of infantile hemangioma: A double-blind randomized controlled trial. Adv Biomed Res 4: 257, 2015.

10. Hogeling M, Adams S and Wargon O: A randomized controlled trial of propranolol for infantile hemangiomas. Pediatrics 128: e259-e266, 2011.

11. Achauer BM, Chang CJ and Vander Kam VM: Management of hemangioma of infancy: Review of 245 patients. Plast Reconstr Surg 99: 1301-1308, 1997.

12. Ji Y, Chen S, Li K, Li L, Xu C and Xiang B: Signaling pathways in the development of infantile hemangioma. J Hematol Oncol 7: $13,2014$.

13. Greenberger S: Infantile Hemangioma[M]//Sex and Dermatology. Springer Cham, New York, NY, pp215-225, 2018.

14. Darrow DH, Greene AK, Mancini AJ and Nopper AJ; Section on dermatology, section on otolaryngology-head and neck surgery, and section on plastic surgery: Diagnosis and management of infantile hemangioma. Pediatrics 136: e1060-e1104, 2015.

15. Chinnadurai S, Fonnesbeck C, Snyder KM, Sathe NA, Morad A, Likis FE and McPheeters ML: Pharmacologic interventions for infantile hemangioma: A meta-analysis. Pediatrics 137: e20153896, 2016.

16. Léaute-Labrèze $C$, Boccara $O$, Degrugillier-Chopinet $C$, Mazereeuw-Hautier J, Prey S, Lebbé G, Gautier S, Ortis V, Lafon M, Montagne A, et al: Safety of oral propranolol for the treatment of infantile hemangioma: A systematic review. Pediatrics 138: e20160353, 2016.

17. Ng M, Knuth C, Weisbrod C and Murthy A: Propranolol therapy for problematic infantile hemangioma. Ann Plast Surg 76: 306-310, 2016.

18. Hou J, Wang M, Tang H, Wang Y and Huang H: Pingyangmycin sclerotherapy for infantile hemangiomas in oral and maxillofacial regions: An evaluation of 66 consecutive patients. Int J Oral Maxillofac Surg 40: 1246-1251, 2011.

19. Huang Y, Li P, Xia S, Zhuo Y and Wu L: Proapoptotic effect and the mechanism of action of pingyangmycin on cavernous hemangiomas. Exp Ther Med 7: 473-477, 2014.

20. Tu JB, Li QY, Jiang F, Hu XY, Ma RZ, Dong Q, Zhang H, Pattar P and Li SX: Pingyangmycin stimulates apoptosis in human hemangioma-derived endothelial cells through activation of the p53 pathway. Mol Med Rep 10: 301-305, 2014.

21. Kwon SH, Choi JW, Byun SY, Kim BR, Park KC, Youn SW, Huh $\mathrm{CH}$ and Na JI: Effect of early long-pulse pulsed dye laser treatment in infantile hemangiomas. Dermatol Surg 40: 405-411, 2014.

22. Kessels JP, Hamers ET and Ostertag JU: Superficial hemangioma: Pulsed dye laser versus wait-and-see. Dermatol Surg 39: 414-421, 2013.

23. Bertoni N, Pereira LM, Severino FE, Moura R, Yoshida WB and Reis PP: Integrative meta-analysis identifies microRNA-regulated networks in infantile hemangioma. BMC Med Genet 17: 4, 2016.

This work is licensed under a Creative Commons Attribution-NonCommercial-NoDerivatives 4.0 International (CC BY-NC-ND 4.0) License. 